\title{
Application of sewage sludge for the production of construction
}

\author{
Aneta Czechowska-Kosacka, ${ }^{1, *}$ \\ ${ }^{1}$ Lublin University of Technology, Faculty of Environmental Engineering, Nadbystrzycka 40B, 20-618 Lublin, Poland
}

\begin{abstract}
The paper presents the studies pertaining to sewage sludges and their mixtures with fly ash to be used as an additive for the manufacturing of construction materials. The studies were carried out using Xray diffraction. The form and morphology of samples as well as the chemical composition in the micro-area were determined using a scanning electron microscope. The obtained results indicate the possibility of using sewage sludges for construction purposes. In the produced mixtures, an increase in the content of anhydrite and rock-forming calcite was noted in relation to the sludge. Production of the construction materials should be preceded with additional strength tests of the obtained product in order to determined the percentage of waste material addition.
\end{abstract}

\section{Introduction}

Municipal sewage sludge constitutes a by-product of wastewater treatment. Heavy metals are the most hazardous toxic substances found in the sewage sludge [1, 2]. The organic-mineral fraction separated from sewage sludge corresponds to approximately $2 \%$ of wastes produced in Poland. Application of sewage sludge is possible after their stabilization. In the wastewater treatment process, the sludge is subjected to biological, chemical and thermal treatment as well as other methods, which will greatly mitigate their putrification and eliminate health, life and environmental hazards. In Poland, the application of sewage sludge on soils has been practised for a long time. The new act of $14^{\text {th }}$ December 2012 and the Regulation of the Minister of Environment of 6 February 2015 on the municipal sewage sludge significantly changed the approach to their application as a fertilizer $[3,4]$. Due to the strict regulations pertaining to the use of sewage sludge for soil fertilization, their management became an issue [5,6]

At present, sewage sludge is disposed of using thermal methods; however, this is an extremely energyconsuming process $[7,8,9,10]$. Another disadvantage of this method is the emission of harmful gases and production of significant amounts of ashes that may be utilized, e.g. in the production of certain construction materials. One of the known methods of wastewater treatment products utilization is their application with fuel of higher calorific value as an alternative fuel for the firing of clinker [11]. The maximum share of sewage sludge in the fuels for clinker production should not exceed 5\% [12]. In the case of heavy metals and other pollution indices, they are permanently incorporated into the clinker structure and they are bound with cement. Another method of sludge management is its ceramization, which aims at waste-free utilization of wastes and limiting the consumption of natural ceramic resources [13, 14].

However, alternative methods of managing sewage sludge, aiming not only at their disposal but also application in the production of a new construction material [15].

The aim of this work is to determine the possibilities of utilizing sewage sludge for the production of construction materials.

\section{Materials and methods}

The sewage sludges from mechanical-biological wastewater treatment plants (WWTP) in the Lublin Voivodeship were employed in the research:

_ "Bieławin" WWTP in Chełm,

_ $\quad$ "Hajdaów" WWTP in Lublin,

- WWTP in Lubartów, as well as the fly ash from "Bełchatów" Power Plant.

The mineral composition of the sewage sludge samples and sludge-fly ash mixtures were analyzed by means of X-ray diffraction using powder method and X'pert APD X-ray diffractometer by Philips and PW 3020 goniometer with $\mathrm{Cu}$ lamp and graphite monochromator. The analyses were conducted in the range of $5-50^{\circ} 2 \Theta$. The diffraction data were prepared usign Philips $X^{\prime}$ 'pert and ClavLab ver. 1.0 software. Identification of mineral phases was based on PCPDFWIN ver. 1.30 database formaliyed by JCPDS-ICDD.

The form and morphology of sewage sludge and sludge-fly ash mixtures in the micro-area were carried out using S-4700 scanning electron microscope (SEM) with field emission by HITACHI, equipped with a VANTAGE system for chemical composition analysis based on dispersion of energy dispersive X-ray spectrometry (EDS) by NORAN. In order to prepare the samples for SEM examinations, they were glued to a carbon holder using carbon glue; then, the preparations were sputtered with

\footnotetext{
*Corresponding author: a.czechowska-kosacka@pollub.pl
} 
approx. $50 \mathrm{~nm}$-thick carbon coating by means of CRESSINGTON sputter coater.

\section{Results and discussion}

The mineral composition of sewage sludge from particular treatment plants is similar (Fig. 1-3). The main component of these sludges is amorphous phase. Its presence on diffractograms is evident from the elevated background ranging from 15 to $35(2 \Theta)$. The mineral composition also includes quartz modified with the characteristic interplanar distances $\mathrm{d}_{\mathrm{hkl}} 3,34$ and 4,26 $\AA$ as well as calcite, recognized by the reflexes: 3,$03 ; 2,89$ and $3,87 \AA$.

As a result of adding fly ash from „Bełchatów” Power Plant to the considered sewage sludges from Chełm, Lubartów and Lublin treatment plants, a clear increase in the anhydrite content was observed, recognized by the strongest reflexes with the values $\mathrm{d}_{\mathrm{hkl}} 2,84 ; 3,49$ and $2,57 \AA$.

While comparing the sewage sludge before and after the solidification process, a visible increase in the calcite content $\left(\mathrm{CaCO}_{3}\right)$ - which is a rock-forming material was noted. The obtained mixtures also contain quartz, feldspar (calcium in the form of aluminosilicates, anorthite $\mathrm{Ca}\left[\mathrm{Al}_{2} \mathrm{Si}_{2} \mathrm{O}_{8}\right]$ ) and ferrous oxides in the form of hematite $\mathrm{Fe}_{2} \mathrm{O}_{3}$. The characteristic interplanar distaces for all identified mineral phases were presented in Table 1.

Table 1. Characteristic interplanar distances dhkl and their respective mineral phases.

\begin{tabular}{|c|c|}
\hline$d_{\text {hkl }}$ & Minerał \\
\hline 4,26 & $\mathrm{Q}$ \\
\hline 4,03 & $\mathrm{Q}$ \\
\hline 3,87 & $\mathrm{~S}+\mathrm{C}$ \\
\hline 3,49 & $\mathrm{~A}$ \\
\hline 3,34 & $\mathrm{Q}$ \\
\hline 3,21 & $\mathrm{~S}$ \\
\hline 3,03 & $\mathrm{C}$ \\
\hline 2,89 & $\mathrm{C}$ \\
\hline 2,84 & $\mathrm{~A}$ \\
\hline 2,70 & $\mathrm{H}$ \\
\hline 2,57 & $\mathrm{~A}$ \\
\hline 2,46 & $\mathrm{Q}$ \\
\hline 2,30 & $\mathrm{~A}+\mathrm{Q}$ \\
\hline 2,24 & $\mathrm{Q}$ \\
\hline 2,20 & $\mathrm{~A}$ \\
\hline 2,13 & $\mathrm{Q}$ \\
\hline 2,09 & $\mathrm{Q}$ \\
\hline 1,99 & $\mathrm{Q}$ \\
\hline 1,91 & $\mathrm{Q}$ \\
\hline 1,87 & $\mathrm{~A}$ \\
\hline
\end{tabular}

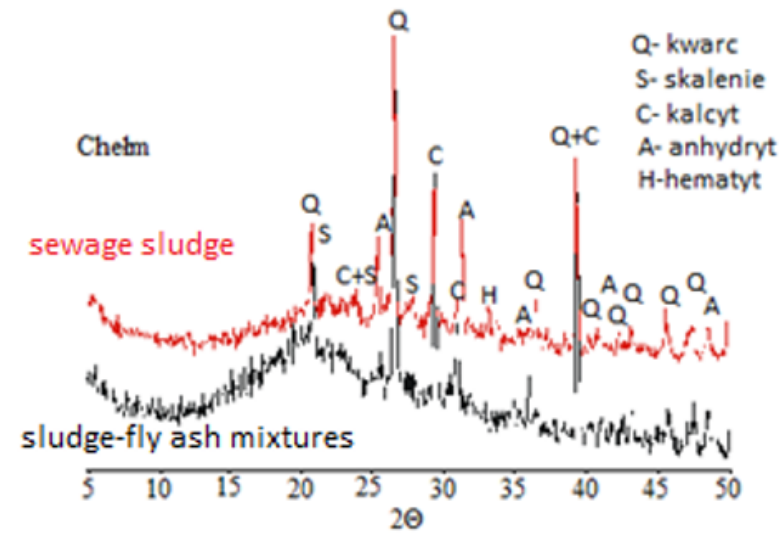

Fig. 1. X-ray diffractogram of sewage sludge from "Bieławin" treatment plant in Chełm and sludge-fly ash mixtures.

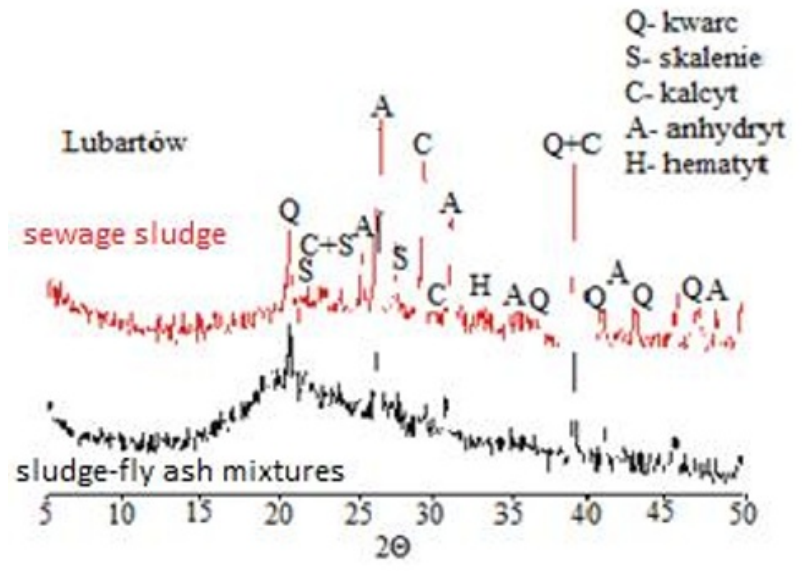

Fig. 2. X-ray diffractogramdiffractogram of sewage sludge from Lubartów treatment plant and sludge-fly ash mixtures.

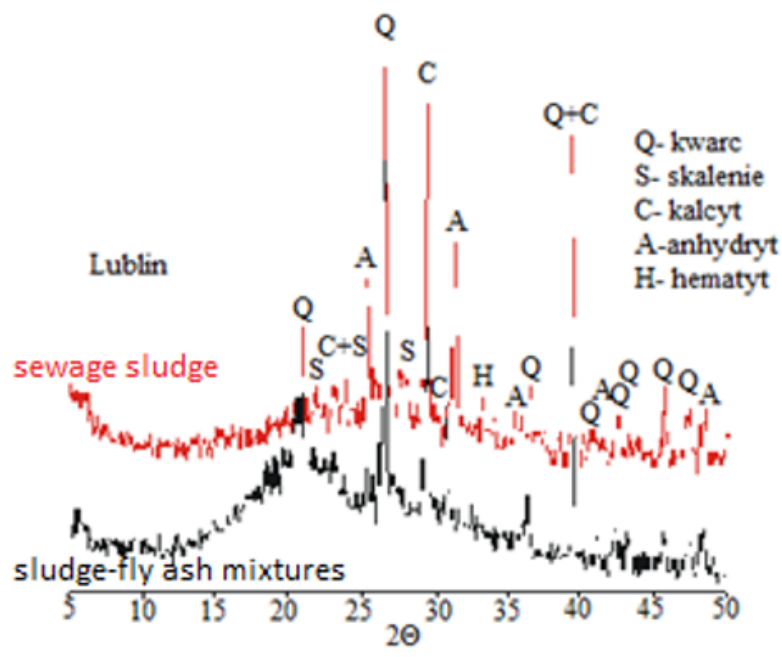

Fig. 3. X-ray diffractogram of sewage sludge from "Hajdów" treatment plant in Lublin and sludge-fly ash mixtures.

The scanning electron microscope (SEM) images clearly show the presence of two mineral substances. Organic matter, which creates irregular, strongly undulating morphological forms, is dominant (Fig.8 analysis 1; Fig. 4, analysis 1). The other substance found 
in the composition of all investigated sewage sludges is calcium-iron phosphate, forming oval clusters (Fig. 8 analysis 2; Fig. 6 analysis 1, 2). Frequently, both substances are strongly interspersed, so that carbon, phosphorus, calcium and iron are dominant in the chemical composition spectra (Fig. 6 analysis 2). Such morphological forms confirm the lack of internal order both in the sewage sludge and mixtures. This is also confirmed by the results of $\mathrm{x}$-ray analyses which clearly indicate the elevated background, characteristic for this type of substance. The mineral composition of all investigated sewage sludges includes quartz (Fig. 4, analysis 2) and calcite, the presence of which is marked by the occurrence of calcium and carbon on the chemical composition spectra (Fig. 8 analysis 2; Fig. 4 analysis 2).

Adding fly ash from brown coal combustion to sewage sludge influences the change of structure and mineral composition of the created mixtures. The main mineral component of these mixtures is anhydrite $\left(\mathrm{CaSO}_{4}\right)$, which creates earthy, lumpy morphological forms, the presence of which is confirmed by chemical analyses with main elements, i.e. sulphur and calcium (Fig. 9 analysis 3; Fig. 5 analysis 2; Fig. 7 analysis 2).
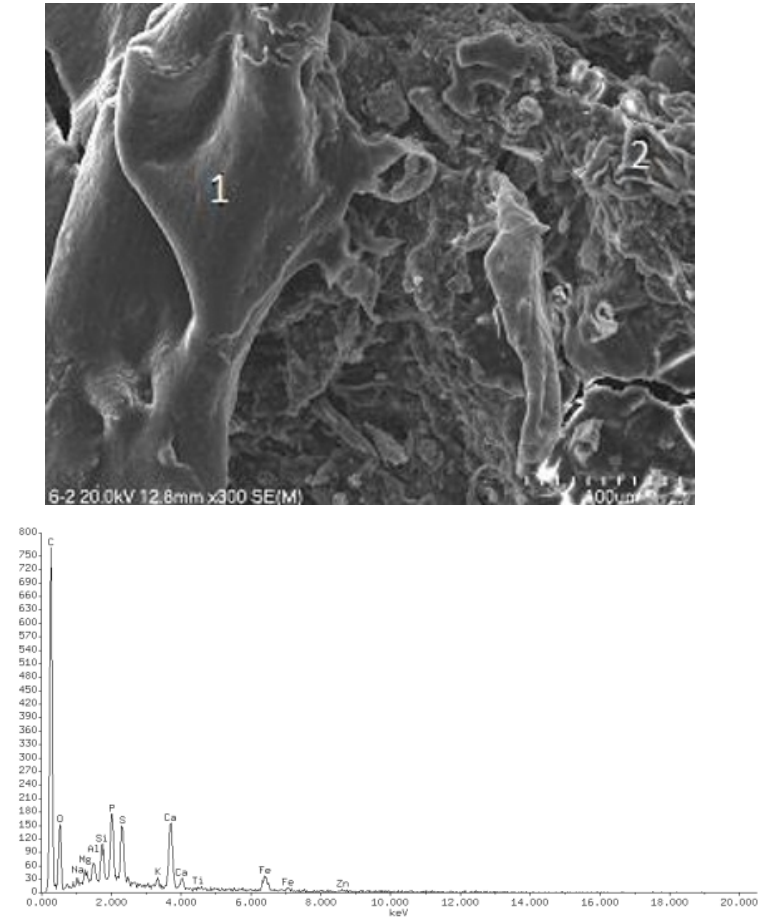

Chemical analysis in point 1

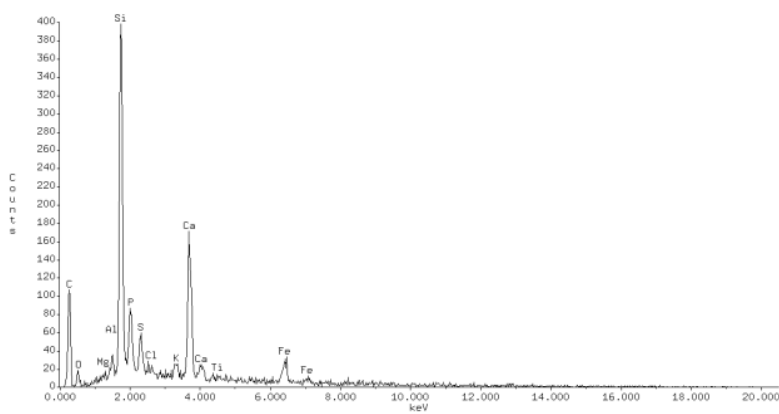

Chemical analysis in point 2

Fig. 4. SEM image of a sewage sludge sample from Chełm and chemical analyses in the micro-area.
In the created mixtures, one can also observe the presence of aluminosilicate enamel, which sometimes creates characteristic forms with spherical shape (Fig. 9 analysis 1, Fig. 7 analysis 1) and much more frequently irregular clusters (Fig 7 analysis 3). The mineral composition also includes quartz (Fig. 5 analysis 3), feldspar (Fig. 5 analysis 1) and calcite (Fig. 9 analysis 2; Fig. 5 analysis 2).
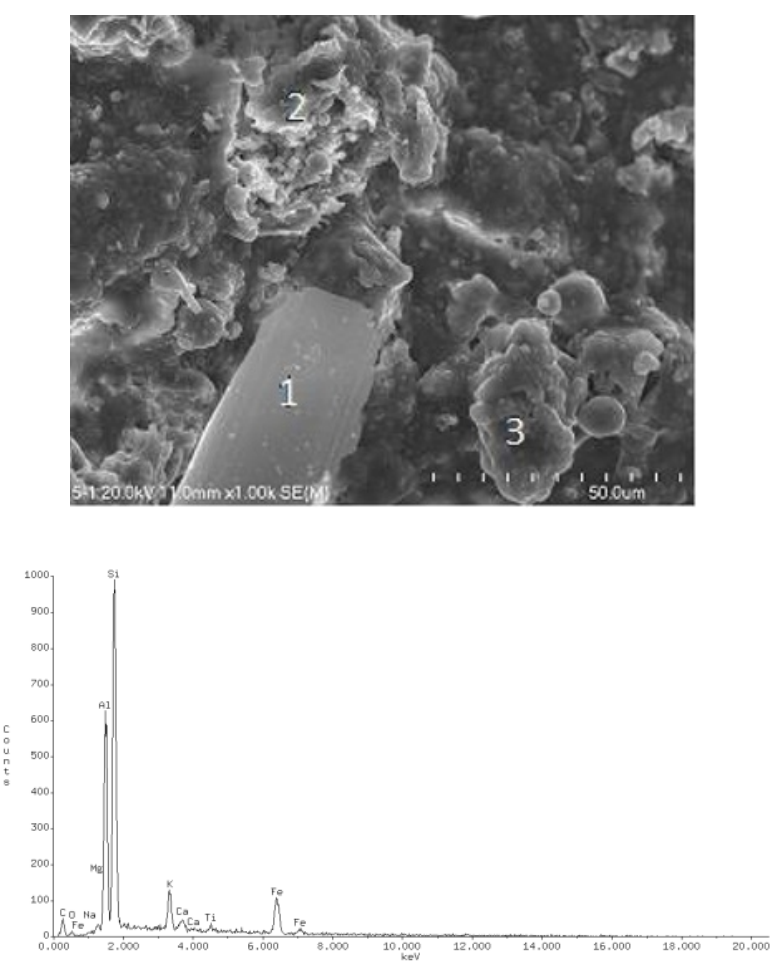

Chemical analysis in point 1

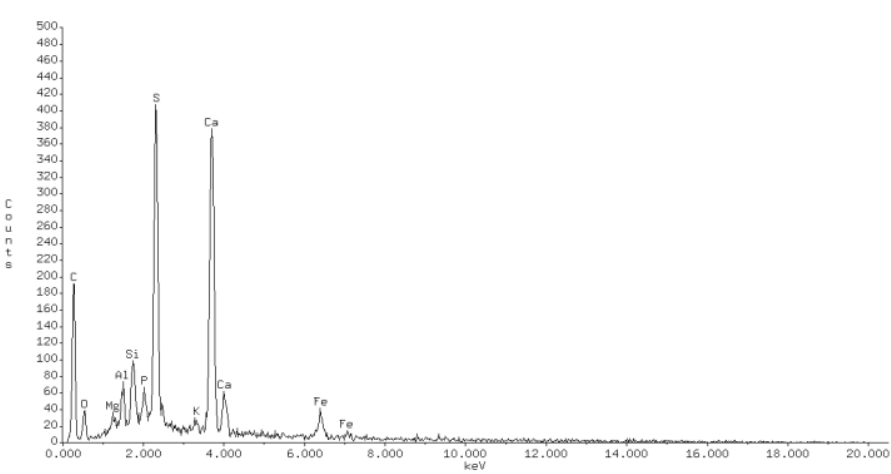

Chemical analysis in point 2

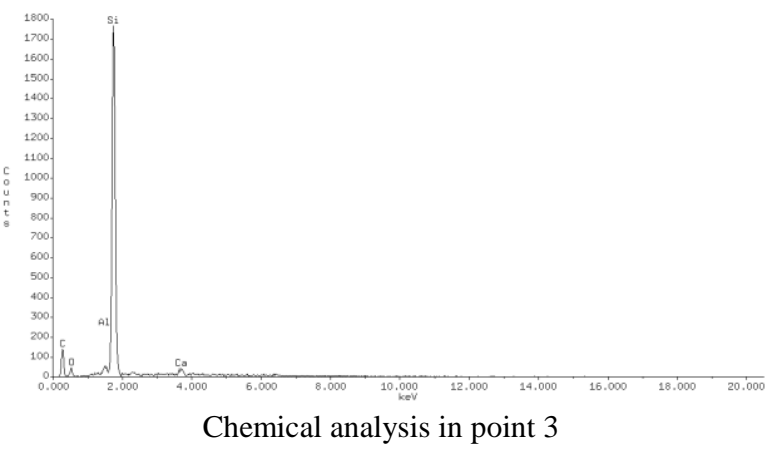

Fig. 5. SEM image of a sewage sludge sample from Chełm with fly ash and chemical analyses in the micro-area. 

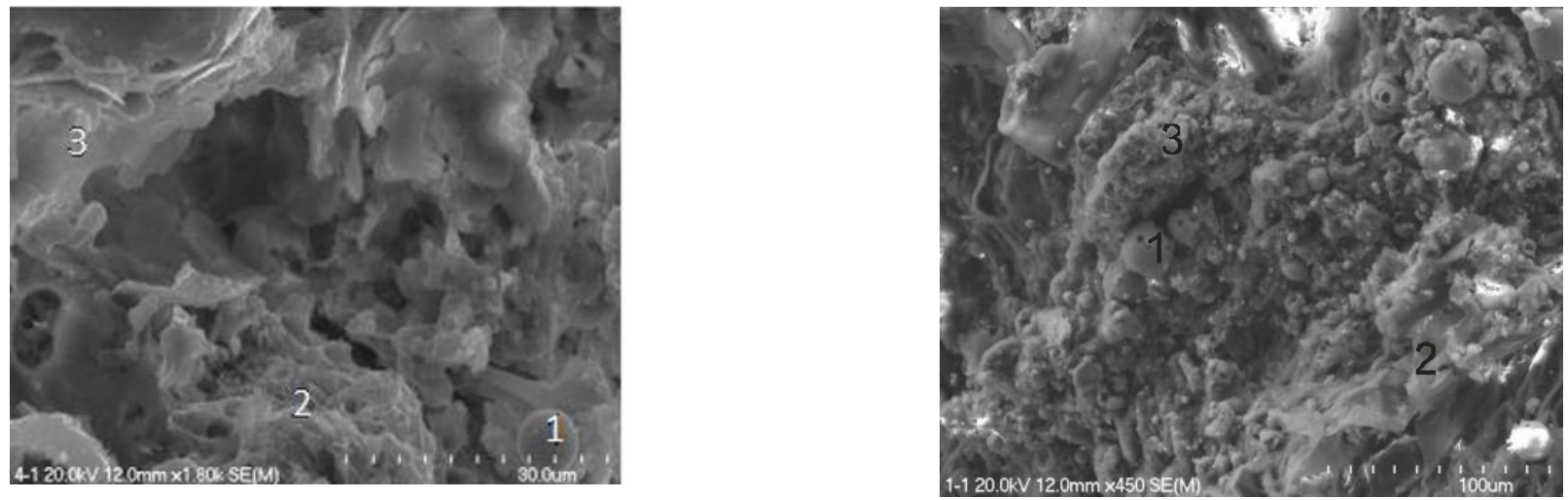

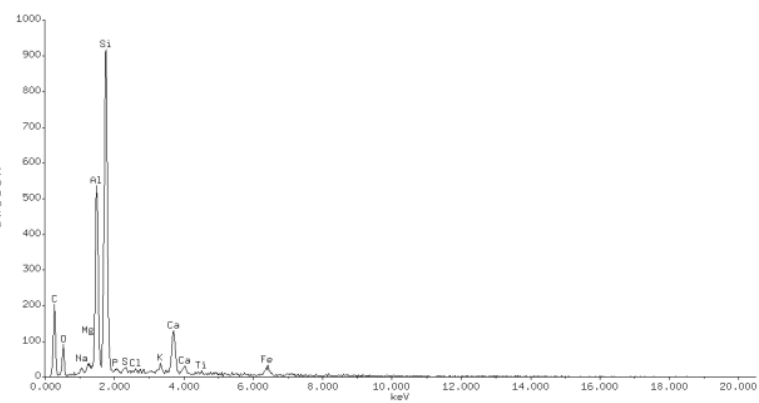

Chemical analysis in point 1

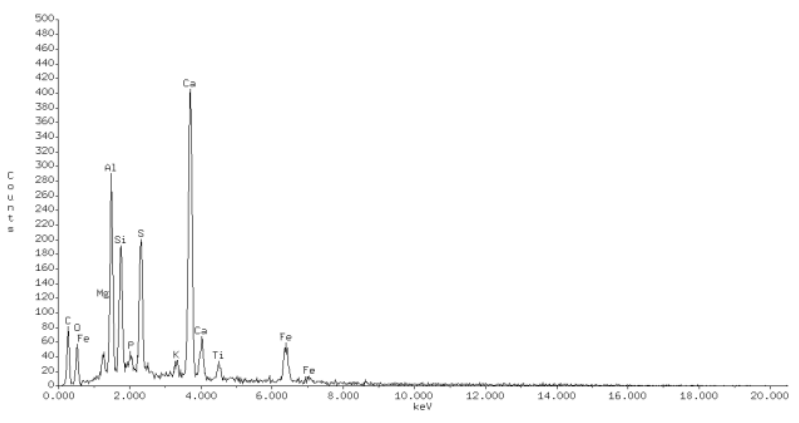

Chemical analysis in point 2

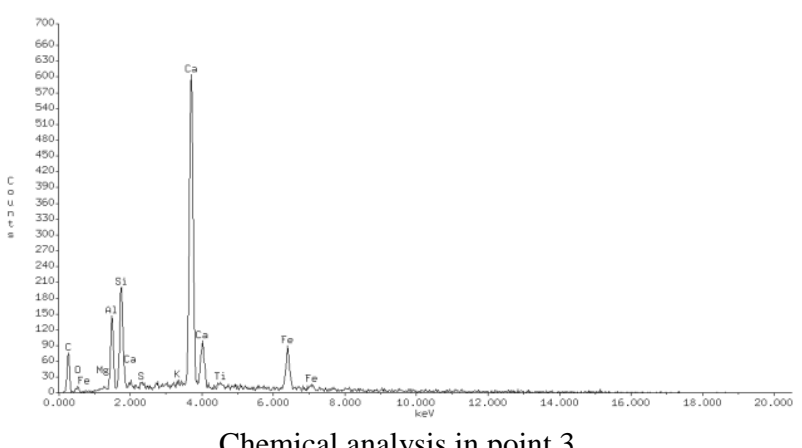

Fig. 7. SEM image of a sewage sludge sample from Lubartów with fly ash and chemical analyses in the micro-area.

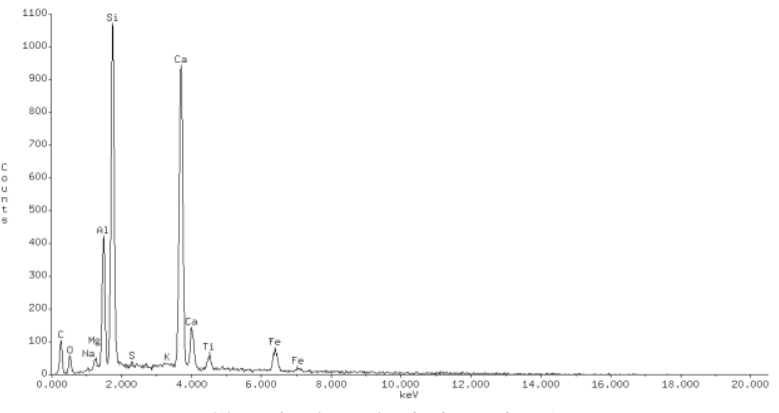

Chemical analysis in point 1

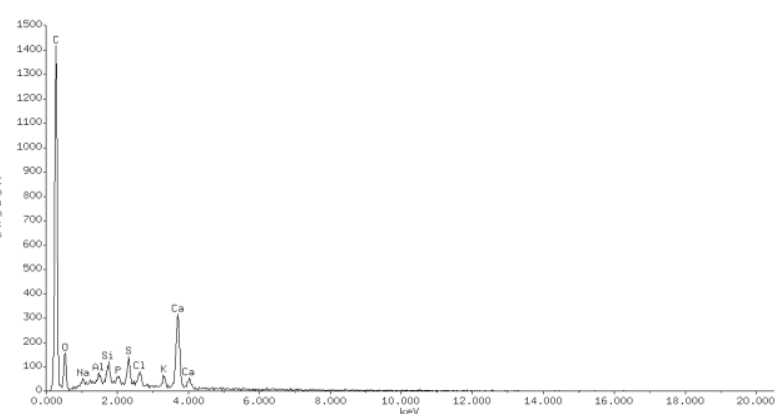

Chemical analysis in point 2

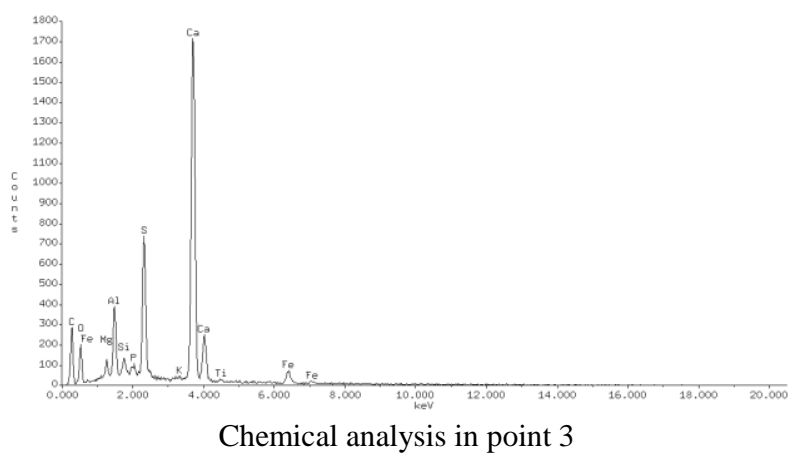

Fig. 9. SEM image of a sewage sludge sample from Lublin with fly ash and chemical analyses in the micro-area. 

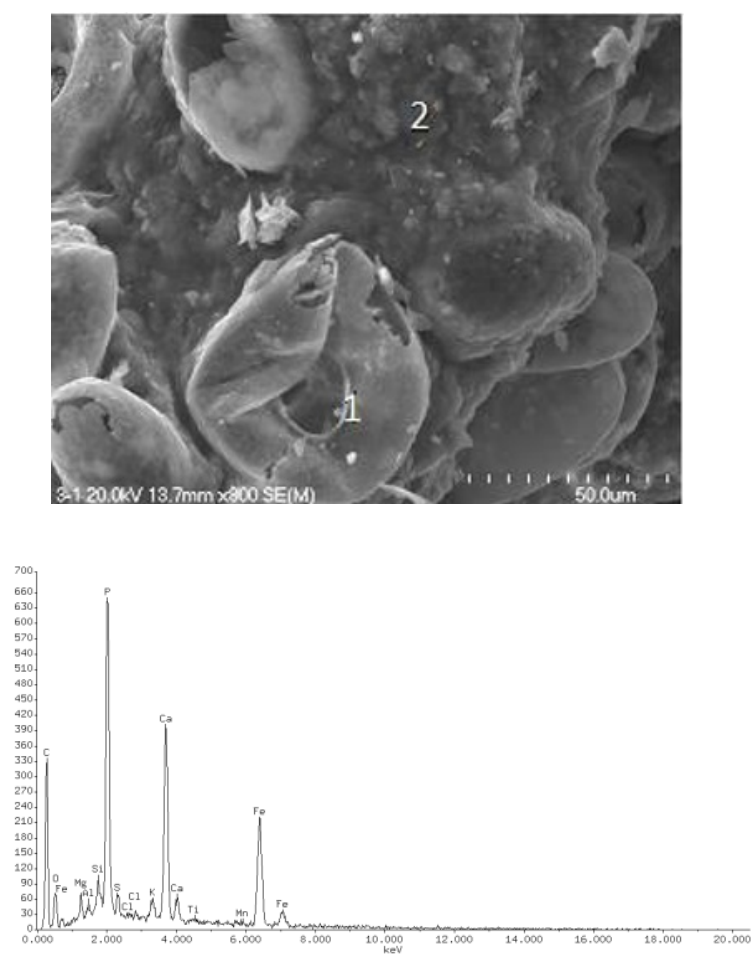

Chemical analysis in point 1

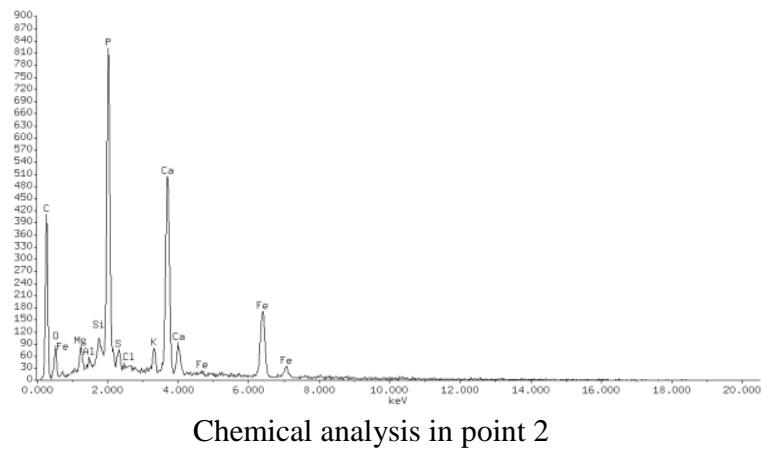

Fig. 6. SEM image of a sewage sludge sample from Lubartów and chemical analyses in the micro-area.

\section{Conclusions}

In accordance with the conducted research, it is possible to draw the following conclusions:

- Significant amounts of sewage sludges produced in wastewater treatment plants encourage seeking new methods of their management. The conducted studies indicated that sewage sludges subjected to treatment, may be applied as a component of construction materials, e.g. cobblestone.

- The studies conducted using X-ray diffraction and confirmed in the scanning electron microscope images, indicated the presence of quartz and calcite. On the other hand, in sludge-fly ash mixtures, an increase in the content of anhydrite and rock-forming calcite was observed.

- Application of sewage sludge for the production of construction materials should be preceded by additional strength tests in order to determine the percentage of waste content.
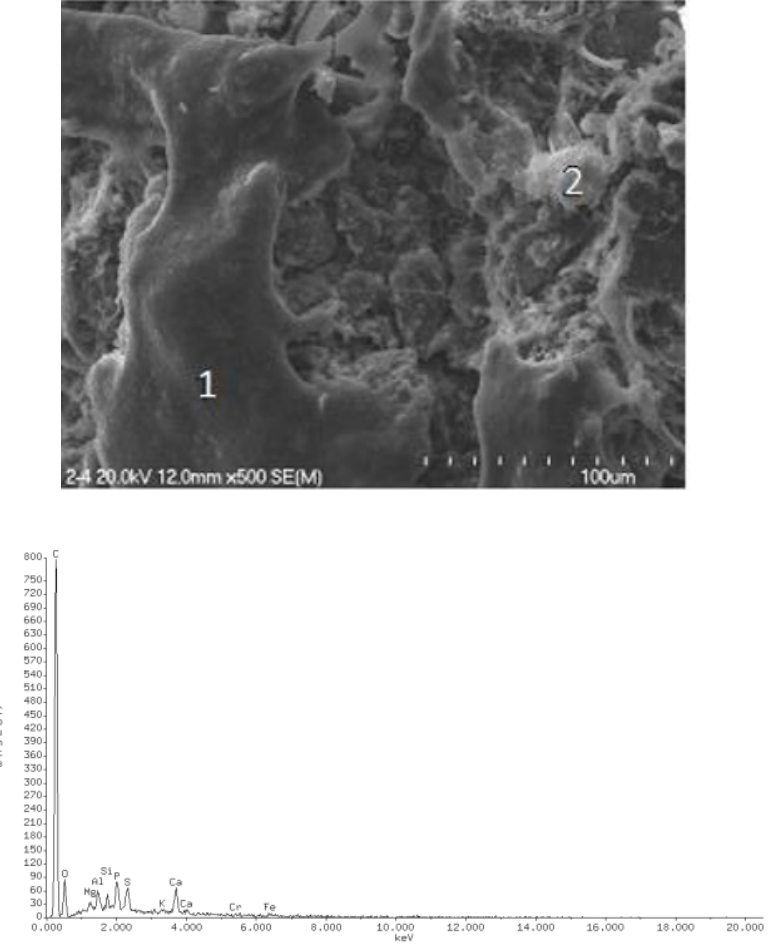

Chemical analysis in point 1

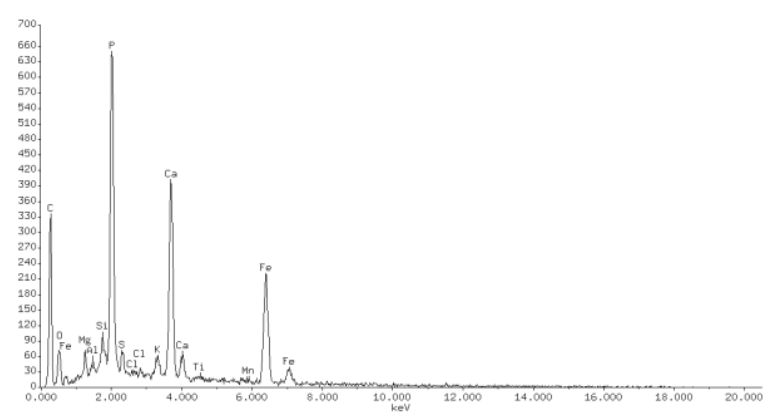

Chemical analysis in point 2

Fig. 8. SEM image of a sewage sludge sample from Lublin and chemical analyses in the micro-area.

\section{References}

1. J. Latosińska, Inż. Och. Środow., 17, 2 (2014)

2. M. De la Guardia, A. Morales-Rubio, Trac-Trend Anal Chem 15, 8 (1996)

3. Act on waste, 2012. Act on wastes dated 14 December 2012

4. Regulation, 2015. Regulation of the Minister of the Natural Environment on municipal sewage sludge dated 6 February 2015. Journal of Laws of Poland, Item 257. Journal of Laws of Poland. No O, Item 21

5. P.S. Kidd, M.J. Domínguez-Rodríguez, J.Díez, C. Monterroso, Chemosphere 66, 8 (2007)

6. Quan-YingCai, Ce-HuiMo, Qi-TangWu, Qiao-Yun Zeng, Athanasios Katsoyiannis, J Hazard Mater. 147, 3 (2007)

7. S. Werle, R. K.Wilk, Renew Energ. 35, 9 (2010) 
8. Z. Kowalski, Z. Wzorek, K. Gorazda, M. Jodko, P. Przewrocki, J. Kulczycka, Minerals \& Energy - Raw Materials Report 18, 3 (2003)

9. T. Pająk, Environ Prot Eng. 39, 2 (2013)

10. S. Werle, Ecol. Chem. Eng. 19, 1-2 (2012)

11. U. Kaantee, R. Zevenhoven, R. Backman, M. Hupa, Fuel Process Technol. 85 (2004)
12. P.H. Shih, J.E. Chang, H.C.Lu, L.C. Chiang, Cem Concr Res. 35, 2110-2115 (2005)

13. K.J. Mun, Constr Build Mater. 21, 7 (2007)

14. C.R. Cheeseman, G.S.Virdi, Resour Conserv Recycl. 45, 1 (2005)

15. D. Fytili, A. Zabaniotou, Renew Sust Energ Rev. 12, 1 (2008) 